\title{
Gliadin IgA Antibody Measurement
}

National Cancer Institute

\section{Source}

National Cancer Institute. Gliadin IgA Antibody Measurement. NCI Thesaurus. Code C147348.

The determination of the amount of gliadin IgA antibody present in a sample. 